\title{
Building an engaged workforce at Cleveland Clinic
}

\author{
This article was published in the following Dove Press journal: \\ Journal of Healthcare Leadership \\ 15 May 2013 \\ Number of times this article has been viewed
}

Joseph M Patrnchak

Cleveland Clinic, Cleveland, $\mathrm{OH}$, USA

Correspondence: Joseph M Patrnchak Cleveland Clinic, 9500 Euclid Avenue, NA \#4, Cleveland, OH 44195, USA

$\mathrm{Tel}+\mathrm{I} 2164441917$

Fax + I 2164440088

Email patrncj@ccf.org
Abstract: Employee engagement is widely recognized as a critical factor in organizational performance. This article examines an ongoing cultural development initiative at Cleveland Clinic designed to significantly increase employee engagement. Key components of this initiative include the introduction of serving leadership, new caregiver wellness and recognition programs, "Cleveland Clinic Experience" training focused on the institution's core mission, and changes in the institutional vocabulary. Since 2008, the results include a dramatic improvement in engagement, as measured by the Gallup $\mathrm{Q}^{12}$ survey, with parallel improvements in patient satisfaction, as measured by the clinic's scores on the Hospital Consumer Assessment of Healthcare Providers and Systems (HCAHPS) survey. In addition to a discussion of the key components of the clinic's engagement initiative, the article provides a partial review of the literature focused on employee engagement as well as a summary of "lessons learned" that may serve as a guide for others facing the challenge of increasing employee engagement in large, mature health care institutions.

Keywords: health care, employee engagement, culture change, hospital performance, patient satisfaction

\section{Introduction}

In 2008, Cleveland Clinic, Cleveland, OH, USA was in the throes of major change. Building on the results of a 2007 McKinsey (New York, NY, USA) study of its strategy and operations, the clinic had launched a comprehensive strategic review (Cleveland Clinic, unpublished data). At the same time, a number of changes had occurred at the executive level, including a new chief operations officer, a new chief human resources officer, and appointment of the clinic's first chief patient experience officer.

Expansion was the order of the day, including two major new buildings about to transform the clinic's main campus in Cleveland, and a state of the art new facility in Abu Dhabi on the drawing boards. Perhaps most significant was the clinic's intense focus on a more patient-centric delivery model. This shift had begun in 2006 with the decision to restructure the clinic around more than 20 institutes, each of which would bring together in one location all the medical specialties related to a particular set of medical issues - eg, cardiovascular, oncology, pediatrics, etc.

The appointment of a chief patient experience officer in 2007 signaled a complementary focus on improving the total patient experience. The urgency around this issue increased in March 2008 when the results of the first federal Hospital Consumer Assessment of Healthcare Providers and Systems (HCAHPS) survey were announced 
and the clinic scored below the national average in several categories of patient satisfaction. ${ }^{1}$

With so much change buffeting the clinic's $40,000+$ employees, the leadership team felt the need for a new "people strategy" and, more broadly, a strategy for making the clinic's organizational culture more conducive to high levels of employee morale and engagement. This paper describes the approach taken and the results to date.

\section{Cleveland Clinic}

In 2012, Cleveland Clinic was ranked \#4 in the US News and World Report survey of US hospitals, with 15 of the clinic's specialties rated among the nation's best. US News has ranked the clinic \#1 in cardiac care for the past 18 years. $^{2}$

Cleveland Clinic includes the Cleveland main campus; eight regional hospitals in northeast Ohio; 15 family health and ambulatory surgery centers; and facilities in Florida, Nevada, Canada, and Abu Dhabi (opening in 2013). In 2012, admissions across the entire system exceeded 160,000 .

Today Cleveland Clinic has over 43,000 employees, including 3100 physicians and scientists and 11,000 nurses. The clinic is distinctive for its staff model, in which all physicians are on salary, and for its delivery model, in which related medical specialties are grouped into 27 unified institutes offering patient-centered care. Renowned for its numerous medical innovations, the clinic is also recognized as a leader in the use of technology and sound management practices to improve hospital efficiency, cost effectiveness, and quality.

\section{Employee engagement}

"Employee engagement" has been defined in a variety of ways. Macey and Schneider, for example, note that:

Common to these definitions is the notion that employee engagement is a desirable condition, has an organizational purpose, and connotes involvement, commitment, passion, enthusiasm, focused effort, and energy, so it has both attitudinal and behavioral components. ${ }^{3}$

Gibbons blended a number of definitions to yield the following:

Employee engagement is a heightened emotional and intellectual connection that an employee has for his/her job, organization, manager, or co-workers that, in turn, influences him/her to apply additional discretionary effort to his/her work. ${ }^{4}$
As to the importance of employee engagement, Ketter points out that:

For several years, employee engagement has been a hot topic

in the executive suite because there is mounting evidence

that employee engagement correlates to individual, group,

and organizational performance in the areas of productivity,

retention, turnover, customer service, and loyalty. ${ }^{5}$

Among the many studies that constitute this "mounting evidence" of engagement's positive impact on organizational health was a 2004 global analysis using data collected from over 50,000 employees in which highly engaged employees were found to perform $20 \%$ better than their less engaged counterparts. They were also $87 \%$ less likely to leave the organization. ${ }^{6}$

\section{Employee engagement in a hospital setting}

How do higher levels of employee engagement affect performance in health care institutions? Reporting on its study of 94 hospitals with more than 130,000 employees, Gallup, Inc, (Washington, DC, USA), indicates that "hospitals with higher levels of engagement also register higher HCAHPS domain performance." ${ }^{\text {T }}$

In a meta-analysis of 199 research studies across 44 industries, Gallup also reported that, when health care units ranking in the upper quartile in engagement were compared to those in the lowest quartile, there was a median $41 \%$ difference in patient safety incidents. ${ }^{8}$

Similarly, in a study of engagement within another major US hospital system, Towers Perrin (now Towers Watson, New York, NY, USA) found that:

\section{[...] hospital employees were more engaged and were more}

satisfied with their pay and benefits, their patients believed

that they received better care and, as a result, were more

willing to recommend the hospital. ${ }^{9}$

In short, there appears to be solid research support for the (perhaps intuitively obvious) idea that highly engaged employees perform better, and their organizations - including health care organizations - perform better across a wide array of metrics.

\section{Employee engagement: key drivers}

A variety of organizational factors have been linked to employee engagement. For example, the Gibbons metaanalysis previously cited ${ }^{4}$ found 26 drivers in its review 
of the literature, with these eight the most consistently mentioned:

- Trust and integrity - how well managers communicate and "walk the talk."

- Nature of the job - is it mentally stimulating day-to-day?

- Line of sight between employee and company performance

- Career growth opportunities

- Pride about the company

- Coworkers/team members

- Employee development

- Relationship with ones manager. ${ }^{4}$

A Towers Perrin study of 35,000 employees in US companies listed these engagement drivers, in order of importance:

[...] management's interest in employees' well-being; challenging work; decision-making authority; evidence that company is focused on customers; [...] advancement opportunities; company's reputation as good employer; collaborative work environment [...]; resources to get job done; input on decision making; and clear vision from senior management about future success. ${ }^{10}$

The primary importance of leadership, and particularly line management, is consistently cited as a major factor in engagement. For example, a UK government report (Secretary of State for Business), based on an extensive review of engagement research and case studies of companies in both the US and UK, noted that:

Engaging managers offer clarity for what is expected from individual members of staff, which involves some stretch, and much appreciation and feedback/coaching and training. The second key area is treating their people as individuals, with fairness and respect and concern for the employee's well-being. ${ }^{11}$

With this background on employee engagement in mind, now let us turn to the specific issue of engagement at Cleveland Clinic.

\section{Employee engagement at Cleveland Clinic} Cleveland Clinic is a physician-led organization, with a strong clinical culture focused first and foremost on clinical excellence. That culture and that focus have resulted in the clinic's consistently being rated as one of the country's, and indeed one of the world's, premier health care institutions. On the other hand, when the measure of performance is expanded to include patient satisfaction and the overall quality of the patient experience, specifically as measured by the HCAHPS survey, the clinic in 2008 had considerable room for improvement.

Recognizing the connection between employee engagement and customer (ie, patient) satisfaction, in 2008 the clinic retained Gallup to conduct an employee engagement survey. Completed in June 2008, the survey indicated that when compared to Gallup's database of health care providers, the clinic as a whole scored only in the 38th percentile, despite the fact that physicians scored in the 85th percentile and the nursing staff, while significantly less engaged, was still right at the average level (50th percentile) (Cleveland Clinic, unpublished data).

When these results were presented to the clinic's executive team, there was immediate support for HR to develop and implement a strategy to "move the needle" on engagement.

\section{The Gallup $Q^{12}$ engagement survey}

The Gallup $\mathrm{Q}^{12}$ instrument is widely used by organizations to quantify and understand their level of employee engagement. The instrument asks an organization's employees to indicate their agreement with 12 statements, using a 5-point scale from "strongly agree" to "strongly disagree." (A sixth category, for "don't know/does not apply," is not scored.)

The $\mathrm{Q}^{12}$ covers such issues as the employee's knowing what is expected of him/her, feeling as if "my opinions seem to count," having the materials needed to succeed, and being encouraged (and having the opportunity) to develop professionally. On the critical question of the employee's relationship with his/her leaders, the $\mathrm{Q}^{12}$ survey asks whether his or her supervisor "seems to care about me as a person" and whether or not he/she has received recognition in the recent past. On what might be considered a "higher" level, the survey asks the employee whether the organization's mission "makes me feel my job is important."

A detailed analysis of the $\mathrm{Q}^{12}$ instrument's statistical validity is available in Gallup's $Q^{12}$ Meta-Analysis, which notes that: "While $\mathrm{Q}^{12}$ is a measure of actionable engagement conditions, its composite has high convergent validity with affective satisfaction and other direct measures of work engagement."

\section{The Cleveland Clinic engagement strategy: key initiatives Changing the institutional vocabulary: "we are all caregivers"}

While physicians and nurses are the primary caregivers in any hospital, the increased focus on the total patient experience, 
and not just the patient's clinical outcome, has drawn attention to the vital role played by other hospital employees. As any hospital executive can attest, a noisy room, an uncomfortable bed, an inaccurate bill, or a negative interaction with a technician can lead to a dissatisfied patient, even if that patient has received outstanding clinical care.

With the recognition that all its employees, including those working in facilities, food services, transport, or accounting, can thus contribute to a given patient's experience - for better or for worse - and with the understanding that a sense of connection to the organizational mission is a strong driver of employee engagement, one of the clinic's key engagement initiatives was to embrace the concept that "we are all caregivers."

The "we are all caregivers" language was first presented to the executive team at a strategic offsite meeting in the spring of 2008. While there was considerable support for the underlying point that all employees played a role in the patient experience, the idea that nonclinical staff could be considered caregivers at first met with some resistance. Ultimately, the support of the CEO was critical to the decision to go forward with implementation.

On the basis of this decision, "employee" was changed to "caregiver" on all communications materials, from ID badges to the clinic website. The CEO, chief patient experience officer, chief human resources officer, and other top leaders wove the "we are all caregivers" theme into their regular presentations to clinic audiences. The Caregiver Celebration program discussed below focused attention on the idea in a tangible way. And ultimately, the idea reached sufficient currency in the organization's institutional vocabulary that the clinic's 2010 annual report was titled We Are All Caregivers.

While a change in language will not necessarily change perception or behavior - for an individual or an institution - it may be an important element in driving such change. For example, in a Wall Street Journal article, Stanford psychology professor Lera Boroditsky discussed cognitive research in regards to how language affects thinking, and concluded that: "It turns out that if you change how people talk, that changes how they think." 12

Woodbury provided a description of how changing the institutional vocabulary at the Arizona Council of the Girl Scouts of America contributed to successful cultural change, noting that:

As we dug (deeper) we discovered just how powerfully our own language had influenced and contributed to our organizational culture. We are still debating whether the language described or created the culture. Perhaps it did both. ${ }^{13}$
At Cleveland Clinic, in addition to the above changes in language, the concept of the "Cleveland Clinic Experience" was also introduced to make explicit the relationship between the caregiver experience and the patient experience - specifically, that a high quality patient experience depends on highly engaged caregivers whose engagement is in turn determined to a significant extent by the quality of their work experience. As indicated on the Cleveland Clinic website:

In the name of empathy, patient satisfaction and employee engagement, "Cleveland Clinic Experience" was introduced in 2010 to continue building a strong base of engaged and committed caregivers who are dedicated to fulfilling

Cleveland Clinic's mission of putting Patients First. ${ }^{14}$

Over a 6-month period, all 43,000+ caregivers at the clinic participated in a Cleveland Clinic Experience training session focused on how to respond with greater empathy to both colleagues and patients. Some 500 caregivers met at each session, working in groups of eight to ten; each group included individuals from different departments and levels, including executives, managers, and physicians. Line managers also received preparatory and follow-up training in how to support and sustain the Cleveland Clinic Experience in their own units.

\section{Serving leadership}

In a 1970 essay entitled The Servant as Leader, management consultant Robert K Greenleaf defined the servant leader's role as "making sure that other people's highest priority needs are being served," noting that:

The servant-leader is servant first[...]. That person is sharply different from one who is leader first, perhaps because of the need to assuage an unusual power drive or to acquire material possessions. ${ }^{15}$

Servant leadership principles have since been applied in organizations ranging from Southwest Airlines, Marriott, Kaiser Permanente, and Starbucks to the US Army, Air Force, and Marines. ${ }^{16-18}$ When the concept of servant leadership was first presented to Cleveland Clinic's CEO, Dr Delos Cosgrove, he expressed his own support but also strongly suggested the idea of a "soft launch." Citing previous unsuccessful attempts to mandate significant change at the clinic, he stressed the importance of first building widespread awareness of servant leadership, with the goal of creating a broad base of support and generating "demand pull" across all levels of leadership. 
With this in mind, the concept of servant leadership was first presented to the executive team - a presentation at which the CEO expressed his personal support - and then to the "Strategic Council," which consists of some 65 senior executives, both clinical and nonclinical. As the discussion spread and support grew, an external consultancy - Third River Partners (Pittsburgh, PA, USA) - was retained to assist in implementing the concept across the organization.

Ken Jennings, the CEO of Third River Partners, has made a slight shift in Greenleaf's original concept, from "servant" leader to "serving" leader. In The Serving Leader: Five Powerful Actions that Will Transform Your Team, Your Business, and Your Community, he emphasizes the serving leader's "upending the pyramid" of power, with a focus on "raising the bar," "running to great purpose," supporting others, and finding ways to remove the barriers that keep them from succeeding. ${ }^{19}$

In retrospect, Jennings' slight change in language from "servant" to "serving" may have helped minimize resistance as the concept was rolled out across the organization, beginning in early 2009 with the clinic's next leadership tier, consisting of some 400 directors. Reaction was generally very positive, among both clinical and nonclinical staff. When first introduced to the idea of serving leadership, many physicians pointed out that they had been trained to "take charge" and make difficult decisions, that their ability and willingness to do so were critical to outstanding patient care, and that this deeply ingrained training made it natural for them to assume a command and control leadership style. At the same time, they also often expressed the feeling that "this idea of serving others is precisely why I went into medicine."

Over time, the concept of serving leadership became more ingrained across the clinic, as serving leader competencies were built into the clinic's performance management system, and all of the clinic's 3000+ managers received serving leader training. By 2012, a new multilevel (supervisor to executive) leadership development program was ready for launch, with serving leadership at the core of the curriculum.

Perhaps most indicative of how serving leadership is becoming embedded in the clinic's culture is the fact that a number of divisions within the clinic have taken the initiative in applying serving leadership to their own needs. These projects range from improving "the awareness of ICU caregivers from all disciplines around the importance of speaking up on poor safety behaviors" to improving service delivery in the IT organization and strategic planning in the pharmacy division.

\section{Mission, vision, and values}

Among its various engagement metrics, the Gallup $\mathrm{Q}^{12}$ survey measures how connected an organization's employees feel to its mission, based on their level of agreement with this item: "The mission or purpose of my organization makes me feel my job is important." Recognizing the importance of this connection, in 2009 Cleveland Clinic launched an initiative to review, update, and standardize mission/vision/values statements across the entire clinic, including the main campus in Cleveland, eight regional hospitals in northeast Ohio, and facilities in Florida, Nevada, and Toronto, Canada.

The result was that all Cleveland Clinic facilities validated the clinic's mission - "Putting Patients First: To provide better care of the sick, investigation into their problems, and further education of those who serve." A new vision statement - "Striving to be the world's leader in patient experience, clinical outcomes, research and education" was adopted across the system. An updated list of values was also adopted, adding "compassion" and "integrity" to the previous list: quality, innovation, teamwork, and service.

Subsequently, the clinic's mission, vision, and values statements were highlighted in internal communications across the organization, and they were incorporated as core elements in the Cleveland Clinic Experience training sessions attended by all clinic caregivers.

The relationship between mission statements and organizational performance has been the subject of considerable research. Based on previous research and their own study at three health care institutions in Belgium, Desmidt and Prinzie concluded that:

Mission statements can only be deemed effective or successful ... if they stimulate organizational members to (a) process the information embedded in the mission statement (ie, the conveyance process), and (b) reach a common understanding about the meaning of the information $[\ldots]$ (ie, the convergence process). ${ }^{20}$

In other words, mission statements have the power to affect how an organization actually operates only when members of the organization actively and jointly come to some agreement on what the statement actually means for them. By promoting active discussion of the new mission, vision, and value statements in the Cleveland Clinic Experience training sessions and other settings, the clinic attempted to stimulate such agreement.

The success of these efforts cannot be directly established, but Figure 1 does provide some interesting data. On the clinic's Gallup surveys for 2008 and 2009, the grand mean 


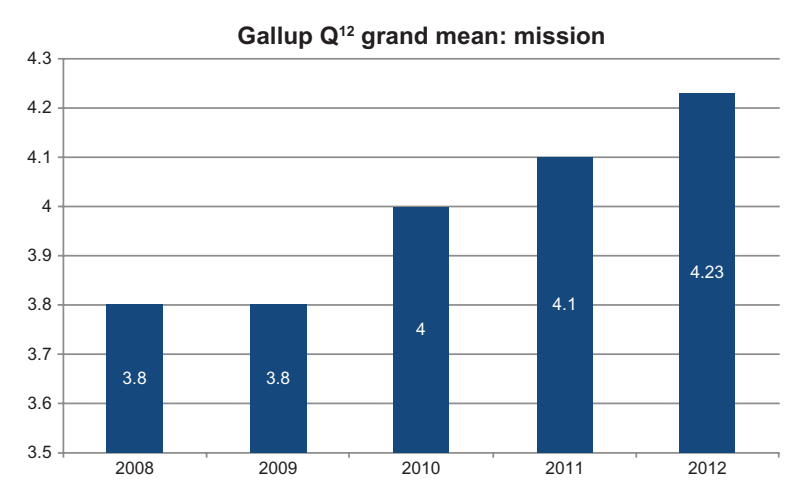

Figure I Employee engagement at Cleveland Clinic (Cleveland, $\mathrm{OH}, \mathrm{USA})$ : $\mathrm{Q}^{12}$ score for "Mission makes me feel my job is important."

for responses to "The mission or purpose of my organization makes me feel my job is important" remained unchanged, at 3.8. In 2010, the year in which the new mission/vision/ values were being highlighted across the organization, including the beginning of the Cleveland Clinic Experience training, the grand mean on this item showed a statistically significant increase to 4.00. In 2011, as the Cleveland Clinic Experience training was completed, the grand mean on this item showed a much greater increase, to 4.10 , and in 2012, the score showed an even greater increase to 4.23.

\section{"Wellness and Well-being:" caring for the caregivers}

As noted in many of the research studies discussed above, the sense that "senior management cares about me" is another key driver of employee engagement. To provide tangible evidence that Cleveland Clinic does indeed care about its employees, the clinic launched a major wellness initiative in 2008.

Finding ways to improve employee wellness has been a high priority of Dr Delos Cosgrove, Cleveland Clinic's CEO, for many years. In 2005, soon after becoming CEO, he implemented a smoke-free policy for all clinic campuses. In 2007, trans fats were banned from employee and patient menus, the clinic's vending machines began a conversion to healthy items, and a decision to no longer hire smokers was announced.

In 2008, with the goal of improving employee engagement as well as employee health, the clinic launched a series of employee-friendly wellness programs, including free weight loss, exercise, and stress reduction programs, offered both on and off-site through partnerships with organizations such as Curves and Weight Watchers. Designed to remove the barriers to access (eg, cost and convenience), the programs also offered small cash incentives for sustained participation.
The response was immediate: 12,500 employees participated in the first year. By the end of 2012, nearly $70 \%$ of the clinic's caregivers had participated (losing a total of over 300,000 pounds in the process).

Over time, the clinic's "Wellness and Well-being" initiative has evolved to include a premium differential that can save employees who participate in the wellness programs up to $13 \%$ on their Employee Health Plan (EHP) premiums. The program has also developed a major focus on the management of chronic diseases such as asthma, diabetes, hypertension, and hyperlipidemia that affect nearly half of the clinic employees and dependents covered by the EHP.

The clinic's wellness program has produced positive clinical results. In addition to the 300,000 pounds lost, these results include significant decreases in hospital admissions and emergency room visits for employees participating in the Chronic Disease Management Program. With these and other positive clinical results have also come annual savings estimated at some US\$14M.

In terms of engagement, a steady flow of unsolicited messages like the one below from a Cleveland Clinic caregiver provides anecdotal evidence that the program has contributed to a greater sense that the clinic does indeed care about the people who work there:

I really am glad that the Clinic has offered this one year Curves membership to us! One of my co-workers and I, both of us from anesthesia engineering, have taken full advantage of it. We joined in February and since then I have lost 8.25 total inches, 11.75 pounds, and 13.05 body fat pounds. Which translates to a loss of $5 \%$ body fat and a decrease in my BMI of 2.08. Thanks again!

\section{"Total Rewards"}

Consistent with the goal of taking tangible steps to demonstrate "caring for the caregivers," since 2008 Cleveland Clinic has utilized a "Total Rewards" strategy that integrates an array of monetary/nonmonetary tools to attract, retain, and engage employees. As part of this strategy, for example, the clinic has raised compensation to market levels for a number of previously undercompensated positions in nursing and allied health (eg, pharmacy, radiology tech, physical therapy). The popular tuition reimbursement benefit has been increased from the bottom quartile of the market to the top $10 \%$. New benefits have been added to the Total Rewards program, including an "Adoption Benefit" to help defray child adoption expenses, and a "Caregiver 
Hardship Program" to assist caregivers facing severe financial difficulty.

Communicating the value of the Total Rewards program to clinic caregivers is a high priority. Every caregiver, for example, has access to "My Total Rewards," an online summary of his/her own Total Rewards package, including the current cash value of base pay, benefits, retirement, wellness programs, "Caregiver Celebrations" awards, etc.

\section{"Caregiver Celebrations"}

While it seems obvious that rewards and recognition are related to engagement, digging more deeply into the issue has produced some interesting findings. Studies by Towers Perrin and the Corporate Leadership Council, for example, found that compensation and benefits, while critical to recruitment and retention, are less important to engagement. ${ }^{4,10}$ On the other hand, a Watson Wyatt (now Towers Watson) survey noted that "The increased use of recognition programs is one way to help keep key talent engaged and motivated," and Derek Irvine in HR Management notes the positive impact of "strategic recognition programs" in a recessionary economy. ${ }^{21,22}$ Similarly, a Watson Wyatt (now Towers Watson) study found that "manager-delivered recognition of employee performance boosts engagement the way a turbocharger cranks up a sports car's horsepower." The study reported that, in organizations with low levels of engagement:

$[\ldots]$ strong manager performance in recognizing employee performance increases engagement by almost $60 \%$, from $33 \%$ of employees giving a favorable engagement score to $52 \% .^{23}$

The most targeted recognition tool available to managers at the Cleveland Clinic is the Caregiver Celebrations program, launched in 2010. Designed to provide clinic managers with an easy way to reward outstanding performance, the program consists of four award tiers:

1. Appreciation: nonmonetary commendation from a manager or peer; 50 recipients each month are selected at random to also receive a $\$ 50$ gift certificate.

2. Honors: cash award from $\$ 10$ to $\$ 100$; manager-driven.

3. Excellence: $\$ 250$ cash or gift certificate awarded to $1 \%$ of the caregiver population each quarter; recipients nominated by institutes/divisions.

4. Caregiver: annual award; 200 nominations enterprisewide; 50 awards of $\$ 2000$; one individual award of $\$ 10,000$; one team award of $\$ 10,000$.
Clinic leaders are urged to use Caregiver Celebrations to "recognize outstanding behaviors and performance that support Cleveland Clinic's values:"

- Quality: maintains the highest standards and achieves them by continually measuring and improving outcomes.

- Innovation: welcomes change, encourages invention and continually seeks better, more efficient ways to achieve goals.

- Teamwork: collaborates and shares knowledge to benefit patients and/or fellow caregivers for the advancement of our mission.

- Service: strives to exceed patients' and/or fellow caregivers' expectations.

- Integrity: adheres to high moral principles and professional standards by a commitment to honesty, confidentiality, trust, respect and transparency.

- Compassion: demonstrates a commitment to world class care by providing a caring, supportive environment for patients, patients' families and fellow caregivers.

- Other: includes any action or performance worthy of recognition that is outside the realm of the six primary Cleveland Clinic values (Cleveland Clinic internal material).

In the first 6 months after launch, clinic managers gave out 33,000 Caregiver Celebration awards, with a cash value of US $\$ 269,000$. In the first 18 months, through 2011, 150,000 awards were handed out, with a value of US\$3M. Another 150,000 awards were made in 2012.

One way to measure the program's effect on engagement is to look at the Gallup survey and the scores on one item in particular: "In the last seven days, I have received recognition or praise for doing good work." 8

As shown in Figure 2, in the first year of the clinic's engagement initiative, the score on this item rose only from a grand mean of 3.24 to 3.25 . Then, in June 2010, the clinic launched the Caregiver Celebrations program, and the Gallup score for that year on this item increased significantly to 3.47. In 2011, the first full year of Caregiver Celebrations, the year-end survey indicated another statistically significant increase for this item, to 3.67. For 2012, the score had risen to 3.83 (Cleveland Clinic unpublished data).

\section{Diversity and inclusion}

In addition to the above programs, which aim at improving the overall caregiver experience and thereby increasing the overall level of caregiver engagement, Cleveland Clinic has also focused on creating a more diverse and inclusive culture, thus helping minority groups and women feel more connected 


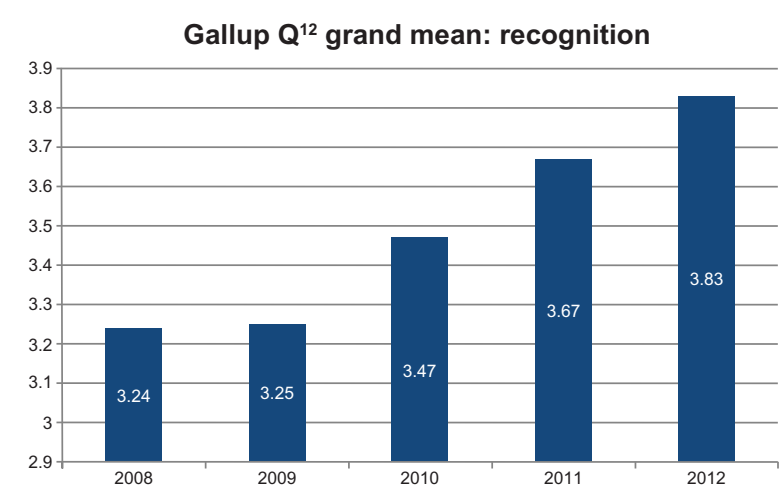

Figure 2 Employee engagement at Cleveland Clinic (Cleveland, OH, USA): $\mathrm{Q}^{12}$ score for "In the last seven days, I have received recognition or praise for doing good work."

to the organization. Efforts have been made to increase development and promotion opportunities for minority and female caregivers. Employee resource groups (ERGs) provide mentoring and help in assimilating to the clinic culture for caregivers from many different backgrounds (African American; Hispanic; Pan-Asian; lesbian, gay, bisexual, transgender [LGBT]; military; etc). The ERGs also offer participants a formal opportunity to share their concerns and perspectives with one another and with senior leadership. The ERGs have shifted from what was previously a focus on social events and cultural celebration to activities more directly linked to strengthening the connection between their members and the clinic's mission. For example, the African-American and Hispanic ERGs have been very active in wellness activities targeting those populations in the Cleveland area.

The results of such efforts are reflected in the clinic's having progressed from \#5 in 2010 for large hospital systems in DiversityInc's annual diversity benchmarks, to \#4 in 2011 and \#3 in 2012 (behind Henry Ford Health System and University Hospitals, and ahead of Mayo Clinic and Massachusetts General Hospital). ${ }^{24}$

It is also worth noting that, as Figure 3 indicates, the increase in Gallup engagement scores for African Americans, Hispanics, Asians, and women at the clinic parallel the increase for the clinic as a whole.

\section{Results}

As shown in Figure 4, Cleveland Clinic's overall score on the Gallup $\mathrm{Q}^{12}$ survey has increased from a grand mean of 3.80 in 2008 to 4.17 in 2012, a 5-year increase that Gallup characterizes as "best practice" level.

The Gallup survey also indicates that the ratio of engaged/ not-engaged/actively disengaged employees at the clinic has shifted dramatically in a positive direction.

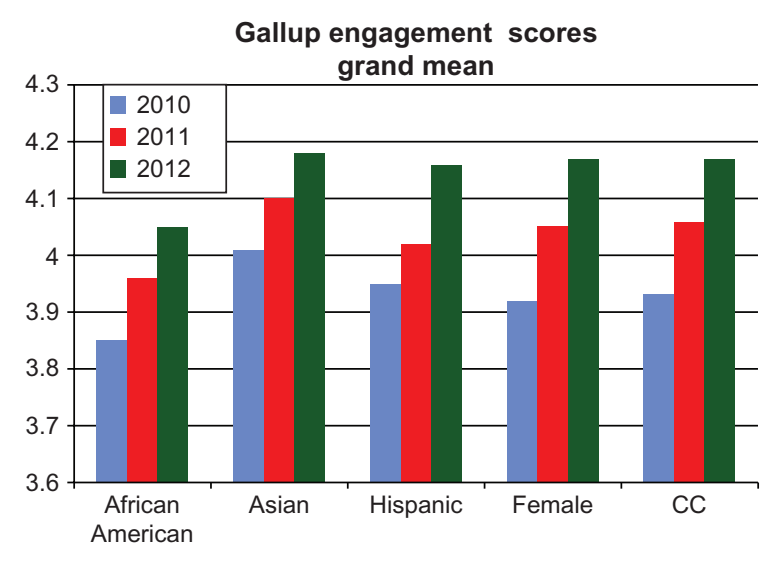

Figure 3 Employee engagement at Cleveland Clinic (Cleveland, OH, USA): by race, ethnicity, and sex.

Abbreviation: CC, Cleveland clinic.

According to Gallup, engaged employees "work with passion." Not-engaged employees "are essentially checked out.” Actively disengaged employees "aren't just unhappy at work; they're busy acting out their unhappiness. Every day these workers undermine what their engaged co-workers accomplish." ${ }^{25}$

Again, according to Gallup, "in world-class organizations the ratio of engaged to actively disengaged employees is $9.57: 1 .{ }^{26}$

As shown in Figure 5, at Cleveland Clinic, the engaged/ actively disengaged ratio has improved from $2.77: 1$ in 2008 to 7.1:1 in 2012. So, while the organization has not yet reached "world class" level in this regard, progress has been substantial.

As in the above discussions of mission/vision/values and Caregiver Celebrations, it is also interesting to examine the changes over time in specific items on the Gallup $\mathrm{Q}^{12}$ survey. In 2008, clinic employees gave their highest agreement rating to "I know what is expected of me at work," followed by "In the last six months, someone at work has talked to me about my progress." Perhaps not surprisingly, since they

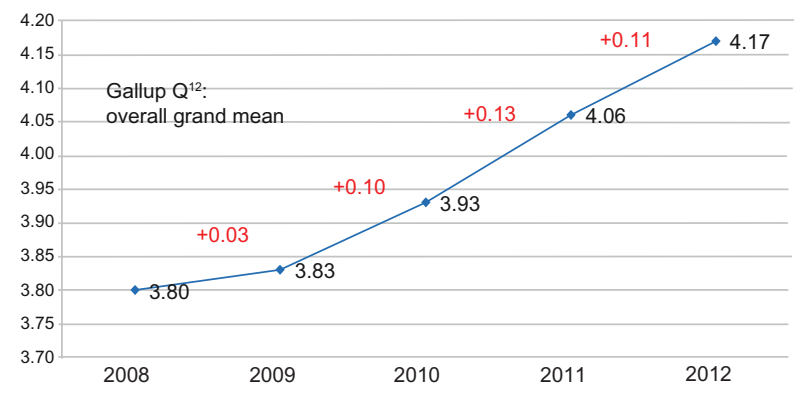

Figure 4 Employee engagement at Cleveland Clinic (Cleveland, OH, USA): overall $\mathrm{Q}^{12}$ score. 


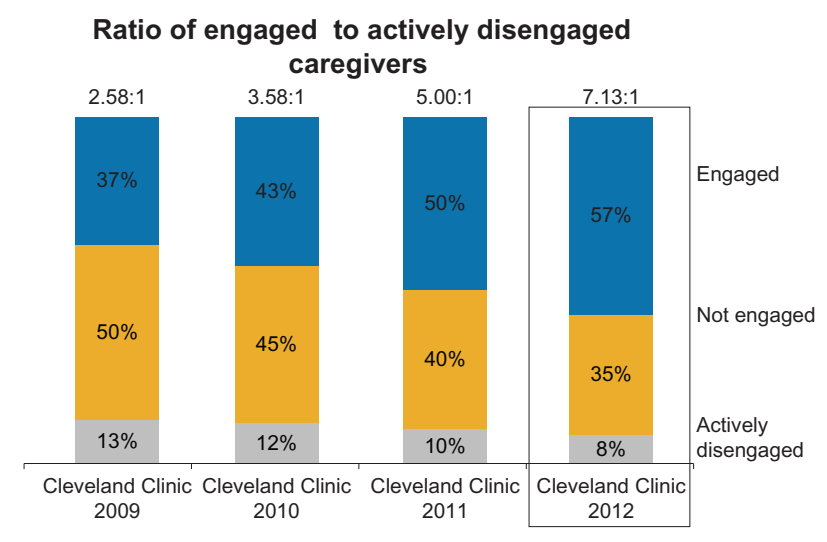

Figure 5 Employee engagement at Cleveland Clinic (Cleveland, OH, USA): ratio of engaged to disengaged.

were highly rated to begin with, these two items have shown the least increase; they were, however, still at the top of the survey in 2012.

On the other hand, in 2008 clinic employees gave by far their lowest agreement rating to "I have a best friend at work." In discussing this item, Gallup notes that:

The best managers do not subscribe to the idea that there should be no close friendships at work; instead, they free people to get to know one another, which is a basic human need. This, then, can influence communication, trust, and other outcomes. ${ }^{8(p .10)}$

In 2008, after "best friend," the following items received the lowest agreement scores:

- In the last seven days, I have received recognition or praise for doing good work;

- At work my opinions seem to count;

- There is someone at work who encourages my development; and

- The mission or purpose of my organization makes me feel my job is important.

Since then, these five items have shown the greatest increase in their grand mean scores, with "best friend" $(+0.74)$ and "recognition" $(+0.58)$ showing by far the greatest improvement. While no direct causal relationship can be proven between the improvement on these measures and the clinic's engagement initiatives, the $\mathrm{Q}^{12}$ data (as discussed above) certainly suggests that refocusing on the clinic's mission/vision/values, the adoption of language such as "we are all caregivers," and the Caregiver Celebrations program have had a positive impact. Similarly, with respect to the improved scores on items such as "best friend," "my opinions count," and "someone encourages my development," it seems reasonable to say that if initiatives such as implementing serving leadership, and creating a new, expanded leadership development program have been effective, one would expect to see significant improvement in precisely these engagement measures.

Equally encouraging - and certainly of great importance in light of the clinic's core mission - the improvement in the clinic's engagement level has been mirrored, as Figure 6 indicates, by a corresponding improvement in patient satisfaction, as measured by its HCAHPS scores, including the overall score and the "would recommend" score.

Finally, Cleveland Clinic's progress toward being "a great place to work and grow" was marked at the end of 2012 by the clinic's being ranked 48th on the Workplace Dynamics list of Top 150 Workplaces in the US. In this survey, 1.7 million employees received questionnaires, and over 1 million employees, from over 4000 companies, responded, making it the largest ever such survey. ${ }^{27}$

\section{Lessons learned}

At this juncture, while Cleveland Clinic's efforts to achieve and sustain high levels of employee engagement are still very much in process, it seems possible to draw at least a few lessons from the experience to date.

\section{Leverage the dissatisfaction}

The "DVF" formula articulated by Beckhard and Harris states that, in order for organizational change to occur, dissatisfaction with the current state (D), a vision of an ideal future state (V), and first steps to achieve the vision (F) must be sufficient to overcome resistance. ${ }^{28}$ At Cleveland Clinic in 2008, dissatisfaction among the leadership team with the Gallup $\mathrm{Q}^{12}$ survey results and the HCAHPS patient satisfaction results helped build the case and generate support for a new engagement strategy.

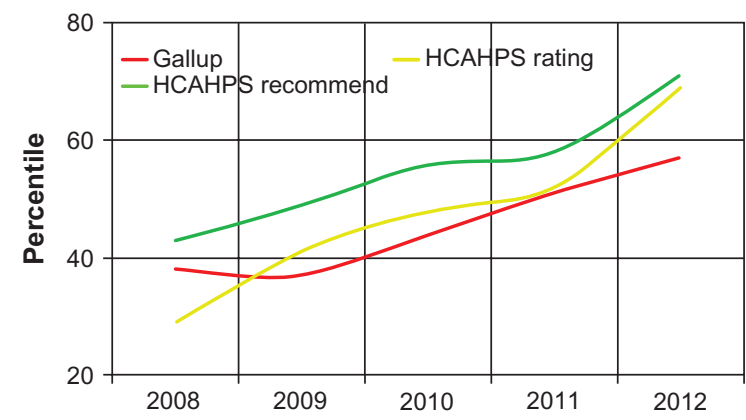

Figure 6 Employee engagement and patient satisfaction at Cleveland Clinic (Cleveland, OH, USA).

Abbreviation: HCAHPS, Hospital Consumer Assessment of Healthcare Providers and Systems. 


\section{Plan for the long haul}

As indicated above, organizational change is never easy to achieve. This is particularly true of a large, complex institution like Cleveland Clinic that has been successful over a long period of time in providing - and being recognized for providing - outstanding clinical results. In addition to the dissatisfaction, vision, and first steps outlined by Beckhard and Harris, ${ }^{28}$ successful change in such an environment will require patience, perseverance, and a long-range perspective. It will also depend on how well the institution can "hardwire" new attitudes and behaviors into the culture. With this in mind, the performance assessment tool used to evaluate all clinic leaders has been modified to include engagement metrics. Today, $25 \%-40 \%$ of a manager's annual evaluation is based on engagement goals.

\section{Focus on a few key initiatives}

As part of their analysis of "the relationship between employee satisfaction and hospital patient experiences," Peltier et al conducted an empirical study in "a major public hospital in New York City [...] located in an urban, residential environment [...] [with] extensive ethnic diversity among employees and patients." 29 In other words, the hospital in the study was similar in many respects to Cleveland Clinic.

Among their conclusions, Peltier et $\mathrm{al}^{29}$ noted the concern of some participants that the hospital's engagement activities often lack consistent follow through. In the words of one participant:

\footnotetext{
"Engagement activities [...] tend to be very intense for a period and then fade away. [...] We seem to try a little of everything, and not focus enough on a few core things or ingredients." 29
}

To avoid this "little of everything" approach, the Cleveland Clinic engagement strategy continues to focus on serving leadership, wellness and well-being, Caregiver Celebration, the Cleveland Clinic Experience, and the core concept that "we are all caregivers."

On the one hand, progress to date suggests that this approach is working. On the other hand, the question inevitably arises: would progress be greater or faster if the "mix" of programs were different? There is no way to definitively answer this question. In practice, the clinic continues to use the Gallup survey to understand the specific drivers of engagement (or disengagement) across the institution and to evaluate/modify its engagement strategy and programs.

\section{Plan and act at the unit level}

Engagement is a local phenomenon. It is built - or not built - at the unit level, in large measure through the day-to-day actions and attitudes of the individual's immediate supervisor. With this in mind, the clinic requires every manager to work with the members of his/her unit to develop a written engagement plan. In 2011, the HR organization reviewed all 4828 of these plans (over a 6-week period), and provided feedback and coaching to every manager to ensure that the plans were appropriately actionable. In 2012, all managers were coached in how to integrate patient experience goals and actions with their engagement plans, with the managers of units with engagement scores in the lowest quartile receiving additional coaching.

To further highlight the key role of unit managers in driving engagement, managers whose units have significantly improved their engagement scores are regularly asked to present their particular experience to the executive team. Feedback on these presentations from both the executive team members and the managers themselves has been extremely positive.

\section{"Socialize" every major new initiative}

In early 2008, the clinic's proposed engagement strategy was first approved by the executive team. Next a small subgroup of key leaders, including the chief medical officer, chief nursing officer, chief patient experience officer, chief human resources officer, and executive director for continuous improvement, met to discuss the issues of engagement and culture development at the clinic. Later, the proposed engagement strategy was presented for discussion to small groups of leaders across the organization for their input. Similarly, specific initiatives such as serving leadership and "we are all caregivers" were first "socialized" in this way in order to generate support before they were introduced across the wider organization.

\section{Seize the "low-hanging fruit" to build credibility}

Wellness and Well-being - specifically, the free access to Weight Watchers, Curves, and other fitness/weight loss programs - was one of the first and most highly visible engagement-related initiatives to be rolled out at the clinic. The immediate, highly positive response to these programs from clinic employees seems to have provided a degree of enhanced credibility that made it easier to win support among the leadership for other initiatives, such as serving leadership and "we are all caregivers." 


\section{Change the institutional vocabulary}

In recent years, Cleveland Clinic's institutional vocabulary has changed as a result of the engagement strategy. Even the term "engagement" itself was not previously part of that vocabulary. The change from "employee" to "caregiver" and the introduction of terms like "serving leadership," and the "Cleveland Clinic Experience," have also helped sustain the focus on making the clinic a "great place to work and grow."

\section{Conclusion}

One of the most critical challenges facing today's health care executive is how to provide a highly satisfactory patient experience - which includes but goes beyond delivering successful clinical outcomes. In effect, a hospital is a service organization, and like any service organization, it must satisfy a variety of emotional, physical, financial, cultural, and other needs if it is to compete successfully. Adding to the challenge is the fact that the government - which now pays the bill for many patients and will pay the bill for many more patients in the future - has made patient satisfaction a criterion for a hospital's acceptance as a service provider.

While more attractive rooms, better food, and other amenities undoubtedly contribute to patient satisfaction, it seems clear that a hospital's level of overall employee engagement has a major impact - positive or negative - on its organizational performance in this regard. With this in mind, Cleveland Clinic has implemented a number of programs focused on improving its employee engagement. This ongoing initiative includes complementing the traditional command and control leadership style with elements of serving leadership; providing new wellness and recognition programs that communicate the clinic's concern for and appreciation of everyone who works there; and changing the institutional vocabulary to recognize that everyone who works at the clinic has a vital role to play in meeting the needs of patients.

After 5 years, the project remains a work in progress. Engagement at the enterprise level, as measured by the Gallup $\mathrm{Q}^{12}$ survey, has improved significantly over this period; patient satisfaction, as measured by the HCAHPS, has improved in parallel. At the same time, the clinic has not yet fully achieved its goal in terms of its overall levels of employee engagement.

On the one hand, these results certainly point to the fact that significant change - the type of change necessary to transform a large workforce from largely disengaged to largely engaged - is not easy and it does not happen overnight. On the other hand, the results also suggest strongly that the types of programs launched at Cleveland Clinic can have a positive impact on employee engagement, and ultimately on patient satisfaction, and that therefore they are well worth consideration by other health care institutions.

\section{Disclosure}

The author reports no conflicts of interest in this work.

\section{References}

1. The Hospital Consumer Assessment of Healthcare Providers and Systems survey is the first national, standardized, publicly reported survey of patients' perspectives of hospital care. The HCAHPS survey asks discharged patients 27 questions about their recent hospital stay. For each participating hospital, ten HCAHPS measures are publicly reported. Webpage on Internet. Centers for Medicare and Medicaid Services, Baltimore, MD. Available at http://www.hcahpsonline.org. Accessed February 6, 2012.

2. Cleveland Clinic. [Webpage on the Internet]. Cleveland. Available from http://my.clevelandclinic.org/p2/us_news_rankings.aspx. Accessed March 20, 2013.

3. Macey W, Schneider B. The meaning of employee engagement Industrial and Organizational Psychology. 2008;1:4. Available at http:// onlinelibrary.wiley.com/doi/10.1111/j.1754-9434.2007.0002.x/abstract. Accessed February 20, 2012.

4. Gibbons J. Employee engagement: a review of current research and its implications. Research report of the Conference Board; New York, NY, 2006:5. Available at http://montrealoffice.wikispaces.com/file/ view/Employee+Engagement+-+Conference+Board.pdf. Accessed February 20, 2012.

5. Ketter P. What's the big deal about employee engagement? $T+D$ Magazine. 2008:45. Available at http://www.astd.org/Publications/ Magazines/TD/TD-Archive/2008/01/The-Big-Deal-About-EmployeeEngagement. Accessed February 20, 2012.

6. Corporate Leadership Council. Driving Performance and Retention Through Employee Engagement. Washington, DC: Corporate Executive Board; 2004:14. Available at http://www.usc.edu/programs/cwfl/assets/ pdf/Employee\%20engagement.pdf. Accessed February 18, 2012.

7. Strengthening Care through Engagement. Gallup; Washington, DC, 2013. Available at http:/www.gallup.com/strategicconsulting/157250/ strengthening-care-engagement.aspx. 2013. Accessed March 8, 2013.

8. Harter J, Schmidt F, Killham E, Agrawal S. Q12 ${ }^{\circledR}$ Meta-Analysis: The Relationship Between Engagement at Work and Organizational Outcomes. Gallup; Washington, DC, USA. 2009:26. Available at http:// www.gallup.com/strategicconsulting/126806/Q12-Meta-Analysis.aspx. Accessed March 5, 2012.

9. Committed to Health: A Large Hospital Network Links Employee Engagement with Patient Satisfaction to Maximize Competitive Strength. Towers Perrin, New York, NY, USA, 2010. Available at: http:// www.towerswatson.com/en/Insights/IC-Types/Case-Studies/2010/ Case-Study-A-Large-Hospital-Network-Links-Employee-Engagement-with-Patient-Satisfaction-to-Maximiz. Accessed February 25, 2012.

10. Working Today: Understanding What Drives Employee Engagement. Towers Perrin; 2003. Available from: http://www.towersperrin.com/ tp/getwebcachedoc?webc=hrs/usa/2003/200309/talent_2003.pdf. Accessed February 17, 2012.

11. MacLeod D, Clarke N. Engaging for Success: Enhancing Performance through Employee Engagement. A Report to UK Department for Business, Innovation, and Skills. London, England, 2009;81. Available at http://dera. ioe.ac.uk/1810/1/file52215.pdf. Accessed February 21, 2012.

12. Boroditsky L. Lost in translation. The Wall Street Journal. July 23, 2010 Available at http://online.wsj.com/article/SB100014240527487034673 04575383131592767868.html. Accessed March 3, 2012. 
13. Woodbury T. Building organizational culture - word by word. Leader to Leader. 2006;39:48-54. Available at http://www.hesselbeininstitute. org/knowledgecenter/journal.aspx?ArticleID=87. Accessed March 3, 2012.

14. Cleveland Clinic Experience. Cleveland, OH: Cleveland Clinic; 2011. Available from: http://my.clevelandclinic.org/Documents/PatientExperience/CC-Experience-5-2011.pdf. Accessed March 23, 2012.

15. Greenleaf RK. The Servant as Leader. Westfield, IN: Greenleaf Center for Servant Leadership; 2008.

16. Spears L. The Understanding and Practice of Servant Leadership, white paper published by Regent University, Hampton Roads, VA, USA, 2005. Available at http://www.regent.edu/acad/global/publications/ sl_proceedings/2005/spears_practice.pdf. Accessed April 20, 2012.

17. Sloan M. Transforming the Air Force: Bridging the Gaps with ServantLeadership. Research report submitted to US Air Force Command and Staff College, Maxwell Air Force Base, AL, USA, April 2009. Available at http://www.dtic.mil/dtic/tr/fulltext/u2/a539701.pdf. Accessed April 20, 2012.

18. Modern Servant Leader.com. Servant Leadership Companies. Available at http://modernservantleader.com/featured/servant-leadershipcompanies-list/. Accessed April 20, 2012.

19. Jennings K, Stahl-Wert J. The Serving Leader: Five Powerful Actions that Will Transform Your Team, Your Business, and Your Community. San Francisco, CA: Berrett-Koehler Publishers, Inc; 2003.

20. Desmidt S, Prinzie A. Does your mission statement have any value? An explorative analysis of the effectiveness of mission statements from a communication perspective. Ghent: Ghent University; 2009. Available from: http://ideas.repec.org/p/rug/rugwps/09-568.html. Accessed February $25,2012$.

21. Effect of the Economic Crisis on HR Programs. Watson Wyatt; 2009:11. Available from: http://www.watsonwyatt.com/temp/pdfs/WT-200913754_oct.pdf. Accessed February 27, 2012.
22. Irvine D. The return on recognition in a recession. HR Management. February 16, 2012. Available at http://www.hrmreport.com/article/TheReturn-on-Recognition-in-a-Recession/. Accessed March 23, 2012.

23. Towers Perrin. The Power of Recognition from Managers: Part 1: The Engagement Engine. April 2009. Available at http://www.towerswatson. com/assets/pdf/629/Manager-Recognition_Part 1_WP_12-24-09.pdf. Accessed Feb 2012

24. Top 5 Hospitals [webpage on the Internet]. DiversityInc, 2013. Available at http://www.diversityinc.com/top5hospitalsystems/. Accessed February $3,2013$.

25. How to Create a Culture of Wellbeing. Gallup Business Journal. 2013. Available from: http://businessjournal.gallup.com/content/159080/ create-culture-organizational-wellbeing.aspx?ref=more. Accessed March 28, 2013.

26. Employee Engagement: What's Your Engagement Ratio? Gallup Consulting; 2010. Available from: http://www.gallup.com/strategicconsulting/121535/Employee-Engagement-OverviewBrochure.aspx. Accessed March 23, 2012.

27. Top 150 - National Top Workplaces 2013 [webpage on the Internet]. Workplace Dynamics; 2013. Available from: http://www.topworkplaces. com/frontend.php/national/standard. Accessed January 30, 2013.

28. Beckhard R, Harris RT. Organizational Transitions: Managing Complex Change. Reading: Addison-Wesley; 1987.

29. Peltier J, Dahl A, Mulhern F. The Relationship between Employee Satisfaction and Hospital Patient Experiences. Forum for People Performance, Management and Measurement; 2009. Available at http:// www.info-now.com/typo3conf/ext/p2wlib/pi1/press2web/html/userimg/ FORUM/Hospital\%20Study\%20-Relationship\%20Btwn\%20Emp.\%20 Satisfaction\%20and\%20Pt.\%20Experiences.pdf. Accessed March 5, 2012.
Journal of Healthcare Leadership

\section{Publish your work in this journal}

The Journal of Healthcare Leadership is an international, peer-reviewed, open access journal focusing on leadership for the health profession. The journal is committed to the rapid publication of research focusing on but not limited to: Healthcare policy and law; Theoretical and practical aspects healthcare delivery; Interactions between healthcare and society and evidence-based practices;

\section{Dovepress}

Interdisciplinary decision-making; Philosophical and ethical issues; Hazard management; Research and opinion for health leadership; Leadership assessment. The manuscript management system is completely online and includes a very quick and fair peer-review system. Visit http://www.dovepress.com/ testimonials.php to read real quotes from published authors. 